\title{
The Presence of Stress, Burnout Syndrome and the Most Important Causes of Working Stress Among Physicians in Primary Health Care - an Observational Study from Banja Luka, Bosnia and Herzegovina
}

\author{
Kosana Stanetić ${ }^{1,3}$, Verica Petrović ${ }^{1,3}$, Brankica Marković1 ${ }^{1}$ Bojan Stanetić ${ }^{2,3}$
}

${ }^{1}$ Primary Health Centre Banja Luka, Bosnia and Herzegovina, ${ }^{2}$ Department of Cardiology, University Clinical Centre of the Republic of Srpska, Banja Luka, Bosnia and Herzegovina, ${ }^{3}$ Medical faculty, University of Banja Luka, Bosnia and Herzegovina

\author{
Correspondence: \\ stanetic.kosana@gmail.com \\ Tel.: + 38765535790 \\ Fax.: + 38751247314
}

Received: 3 August 2018 Accepted: 22 April 2019

Key Words: Stress - Burnout Syndrome the Main Causes of Stress • Primary Care Doctors.
Objective. To investigate the level and causes of stress and the risk of onset of burnout syndrome among physicians employed at the Primary Health Care Centre, Banja Luka. Subjects and Methods. Between March 1, 2018, and May 31, 2018 all physicians from the Primary Health Care Centre, Banja Luka were offered the following questionnaires to fill in: a socio-demographic questionnaire, a questionnaire for self-assessment of the level of stress and the Maslach Burnout Inventory for assessment of the risk of burnout syndrome. Results. Out of 211 physicians, $85.8 \%$ were female. A high level of stress was found in $77.7 \%$ of the subjects. Older doctors had higher levels of emotional exhaustion compared to younger doctors with a shorter length of service $(r=0.236$, $\mathrm{P}=0.01$ ). Emotional exhaustion was significantly correlated with a high level of depersonalization, a low level of personal accomplishment and a high level of stress $(r=0.380, r=-0.174$ and $r=0.574, P=0.01, P=0.04$ and $\mathrm{P}<0.01$, respectively). Depersonalization correlated with a low level of personal accomplishment and stress ( $r=-0.347$ and $r=0.283, P<0.01$ and $\mathrm{P}=0.01$, respectively), while the level of personal accomplishment was in a negative correlation with stress $(\mathrm{r}=-0.281, \mathrm{P}=0.01)$. A high stress level was associated with a high degree of emotional exhaustion (OR 56.543; 95\% CI 11.35-213.09; $\mathrm{P}<0.001$ ) as well as lack of personal accomplishment (OR 0.155; 95\% CI 0.04-0.50; $\mathrm{P}=0.003$ ). Conclusion. A high level of stress was associated with older age, female gender, as well as with a high degree of emotional exhaustion and a lack of personal accomplishment. Preventive measures are warranted.

\section{Introduction}

Burnout syndrome is chronic working stress that manifests in three dimensions (increased emotional exhaustion, an increased level of depersonalization, and a sense of reduced personal accomplishment). This problem often occurs in persons whose profession demands permanent contact with other persons. Health care work is one of the professions with a high risk for development of burnout syndrome (1). The etiopathogenesis of burnout syndrome is complex, but it is generally believed that prolonged "negative stress" is a key factor in its onset. The individual characteristics of each person and the inability to overcome the stress successfully also have an important role. The 
negative feelings of persons with a high level of burnout syndrome are correlated with a loss of sense for professional duties, a loss of capability for self-realization, and a loss of personal perspective. The feeling of the absurdity of existence and the loss of interest in anything happening around them, influence all spheres of the life of a person with burnout syndrome. If the person is in this state for a long period of time, they will lose the ability to enjoy life, and the life quality of these persons is significantly reduced (2).

The medical profession is specific, because doctors make a highly emotional contribution to solving the most subtle physical, psychological and social problems of their patients. A doctor's social contacts are not only towards patients but also towards their co-workers, superiors, their patients' parents and relatives, and others (3).

The following are deemed to be the most common causes of stress at work: interpersonal relationships in the workplace (relationships with patients, colleagues, and supervisors), satisfaction or dissatisfaction with work, possible conflict situations at work, insufficient training for performing tasks at work, overwork, unrealized promotion, etc. (4). The results of the majority of studies conducted show that high levels of stress and burnout syndrome are related to younger age, female sex, negative marital status, long working hours, low job satisfaction, financial worries, sleep deprivation, feelings of responsibility, difficulties in collaborating and other possible factors (5-7).

The aims of this study were to investigate the level of stress and the risk of burnout syndrome onset among physicians employed at the Primary Health Care Centre, Banja Luka, and to identify the most common causes of stress at work.

\section{Subjects and Methods}

The research was an observational study, conducted by interviewing doctors at the
Primary Health Care Centre, Banja Luka. The research was anonymous and voluntarily, and all subjects were informed about the purpose and importance of the research by the authors. All employed doctors were given the following questionnaires: a sociodemographic questionnaire, a questionnaire for self-assessment of the level of stress (8), a questionnaire about the most frequent causes of stress at work, and the Maslach Burnout Inventory $(9,10)$. The study was conducted in the period from 1st March to 31st May 2018. Participants had enough time to fill in the questionnaires autonomously during their break at work. After interviewing, all the obtained data were entered into an Excel database, and then statistically processed using the SPSS programme (Statistical Package for Social Science software, version 23.0).

\section{Subjects}

The study included 211 doctors, out of a total of 246 employed at the Primary Health Care Centre, Banja Luka (response rate 85.77\%). Physicians employed in different departments, with various specialities were interviewed: 127 doctors in family medicine, 22 doctors in emergency care, 4 psychiatrists, 4 epidemiologists, 5 physiatrists, 7 gynaecologists, 13 paediatricians, 5 radiologists, 3 specialists in medical biochemistry and 21 dentists. For the sake of statistical processing, the subjects were divided into three groups in relation to age: those younger than 42 years, those aged from 43 to 51 years, and subjects 52 years and older. In relation to length of service, three groups of subjects were formed: subjects with up to 13 years' service, subjects with from 14 to 23 years' service and subjects with 24 years' service or more.

\section{Questionnaires and Measuring}

As research tools, we used a socio-demographic questionnaire, a questionnaire for 
self-assessment of the level of stress (8) and the Maslach Burnout Inventory $(9,10)$. The socio-demographic questionnaire included data about gender, age, work place, length of service, marital status and the number of children in the family. The questionnaire for self-assessment of the level of stress contained ten questions, and included four basic factors of overwork (chronic lack of time, exaggerated responsibility, lack of support and exaggerated self-expectations and expectations from colleagues and others). The subjects could answer the questions as follows: almost always (4), often (3), rarely (2) and almost never (1). The total scores were obtained by adding up points, and the maximum score was 40 . Subjects whose total score was between 25 and 40 were deemed to have high levels of stress, while subjects whose total score was less than 25 had stress within the normal range.

The original version of the Maslach Burnout Inventory contains 22 questions to which subjects answer as follows: never (0 scores), a few times a year (1), once a month (2), a few times a month (3), once a week (4), a few times a week (5) and daily (6). All the questions were divided into three subscales that serve as indicators for evaluating the level of emotional exhaustion, depersonalization and personal accomplishment. The first subscale, for measuring emotional exhaustion levels, accentuates exaggerated requests directed towards service providers. The second subscale measures the presence of depersonalization that characterizes a negative relationship between service providers and receivers. The third subscale measures levels of personal accomplishment. Emotional exhaustion is evaluated by the answers to nine questions, and the maximum score is 54 (score $<17$ indicates low, 18-29 moderate, $>30$ high emotional exhaustion level). Depersonalization is tested by five questions, and the maximum score is 30 (a score $<5$ indicates low, 6-11 moderate, and $>12$ high depersonalization levels), and personal accomplishment is evaluated by answers to eight questions. The maximum score is 48 (a score $<33$ indicates high, 34-39 moderate, $>40$ low levels of personal accomplishment).

\section{Ethics Statement}

Approval for conducting the study was obtained from the Primary Health Care Centre director and the Ethics Committee of the Primary Health Care Centre, Banja Luka. This research was conducted according to the Helsinki Declaration.

\section{Statistical Analysis}

Data obtained in this research were statistically processed using the SPSS programme version 23.0. Descriptive analysis, in the form of frequencies and percentages, was used for sample analysis and analysis of answers to each question individually. Continuous variables between groups were compared by the Student's $t$ test for normally distributed values; otherwise the Mann Whitney $\mathrm{U}$ test was used. The relationship of variables was analysed by Pearson's coefficient of linear correlation. Odds ratios (OR) and $95 \%$ confidence intervals (CI) assessing the risk of being less stressed were assessed by logistic regression. The following parameters were evaluated in a multivariable model: age, gender, length of service and number of children in family (model 1) as well as all variables from model 1 , plus emotional exhaustion, depersonalization and personal accomplishment in model 2 . In the analytical methods applied, the level of significance was $\mathrm{P}<0.05$.

\section{Results}

The research is an observational study that included 211 physicians employed at the 
Primary Health Care Centre, Banja Luka. There were $85.8 \%$ female subjects. Considering age and length of service, three groups of subjects, that included an approximately equal number of doctors, were formed respectively. The majority of doctors interviewed were married $(77.7 \%)$, and the largest number of them had two children in their family $(30.3 \%)$ (Table 1 ).

The results of the questionnaire for selfassessment of stress levels showed that the largest number of doctors interviewed 164

Table 1. Socio-Demographic Data of Subjects

\begin{tabular}{lll}
\hline Variables & N & $\%$ \\
\hline Gender & & \\
\hline Male & 30 & 14.2 \\
\hline Female & 181 & 85.8 \\
\hline Age (years) & & \\
\hline$<42$ & 72 & 34.1 \\
\hline From 43 to 51 & 65 & 30.8 \\
\hline 52 and more & 74 & 35.1 \\
\hline Years of service & & \\
\hline$<13$ & 71 & 33.6 \\
\hline From 14 to 23 & 69 & 32.7 \\
\hline 24 and more & 71 & 33.7 \\
\hline Marital status & & \\
\hline Married & 164 & 77.7 \\
\hline Unmarried & 27 & 12.8 \\
\hline Divorced & 15 & 7.1 \\
\hline Widowed & 5 & 2.4 \\
\hline Number of children in family & & \\
\hline No children & 37 & 17.5 \\
\hline One child & 64 & 30.3 \\
\hline Two children & 95 & 45.1 \\
\hline Three children & 15 & 7.1 \\
\hline
\end{tabular}

(77.7\%) met the criteria for a high level of stress. The interviewed doctors answered questions about the most frequent causes of stress at their work places. Analysis of the obtained results showed that the most common causes of stress in the interviewed group of doctors were: administrative burden (43.7\%), constant changes to legislation (36.4\%), overwork with a large number of patients $(36.0 \%)$ and health care insurance demands (29.9\%).

The results from the Maslach Burnout Inventory showed that $20.9 \%$ of subjects had a high level of emotional exhaustion, $43.2 \%$ a high level of depersonalization, and 36.9\% a low level of personal accomplishment (Table 2).

A significant correlation was found between the level of emotional exhaustion and age using Pearson's coefficient of linear correlation, where older doctors had higher levels of emotional exhaustion compared to younger doctors $(\mathrm{r}=0.236, \mathrm{P}<0.01$, Table 3$)$.

Emotional exhaustion was significantly correlated with a high level of depersonalization, a low level of personal accomplishment and a high level of stress $(r=0.380, r=-0.174$ and $\mathrm{r}=0.574, \mathrm{P}=0.01, \mathrm{P}=0.04$ and $\mathrm{P}<0.01$, respectively). Depersonalization correlated with a low level of personal accomplishment and a high level of stress $(r=-0.347$ and $\mathrm{r}=0.283, \mathrm{P}<0.01$ and $\mathrm{P}=0.01$, respectively), while the level of personal accomplishment was in a negative correlation with a high level of stress $(\mathrm{r}=-0.281, \mathrm{P}=0.01)$.

As mentioned above, 47 out of 211 subjects showed a low level of stress (22.3\%). In the multivariable logistic regression analysis

Table 2. The Degree of Burnout Syndrome Risk in All Three Dimensions

\begin{tabular}{lllllll}
\hline \multirow{2}{*}{ Degree of burnout } & High & \multicolumn{7}{c}{ Moderate } & \multicolumn{2}{l}{ Low } \\
\cline { 2 - 7 } & $\mathrm{N}$ & $\%$ & $\mathrm{~N}$ & $\%$ & $\mathrm{~N}$ & $\%$ \\
\hline Emotional exhaustion & 44 & 20.9 & 55 & 26.1 & 112 & 53.0 \\
\hline Depersonalization & 91 & 43.2 & 71 & 33.6 & 49 & 23.2 \\
\hline Personal accomplishment & 66 & 31.3 & 67 & 31.8 & 78 & 36.9
\end{tabular}


Table 3. Correlations of Age and the Number of Children in the Family with the Level of Stress and Components of Burnout Syndrome*

\begin{tabular}{llllll}
\hline Variables & Age & $\begin{array}{l}\text { Children in the } \\
\text { family }\end{array}$ & $\begin{array}{l}\text { Emotional } \\
\text { exhaustion }\end{array}$ & Depersonalization & $\begin{array}{l}\text { Personal } \\
\text { accomplishment }\end{array}$ \\
\hline Children in the family & $0.330^{\ddagger}$ & - & - & - & - \\
\hline Emotional exhaustion & $0.236^{\ddagger}$ & $0.115^{*}$ & - & - & - \\
\hline Depersonalization & 0.007 & 0.018 & $0.380^{\ddagger}$ & - & - \\
\hline Personal accomplishment & 0.053 & 0.013 & $-0.174^{\S}$ & $-0.347^{\ddagger}$ & - \\
\hline Stress & 0.093 & 0.035 & $0.574^{\ddagger}$ & $0.283^{\ddagger}$ & $-0.281^{\ddagger}$ \\
\hline
\end{tabular}

"Pearson's coefficient of linear correlation; ${ }^{\dagger}$ Number of children in the family; ${ }^{\ddagger}$ Correlation is significant at the 0.05 level $\left(2\right.$-tailed); ${ }^{\S}$ Correlation is significant at the 0.01 level (2-tailed).

Table 4a. Model 1: Multivariable Logistic Regression for Associated Factors of Being "Less Stressed"

\begin{tabular}{llllllll}
\hline Variables & $\mathrm{B}^{*}$ & S.E. & Wald & df & OR & $95 \% \mathrm{Cl}$ & P-value $^{\dagger}$ \\
\hline Age & -0.082 & 0.020 & 6.360 & 1 & 0.921 & $0.87-0.96$ & 0.023 \\
\hline Gender & 1.000 & 0.420 & 5.669 & 1 & 2.718 & $1.14-5.95$ & 0.029 \\
\hline Number of children in family & 0.021 & 0.209 & 0.010 & 1 & 1.021 & $0.74-1.72$ & 0.821 \\
\hline
\end{tabular}

+ Statistically significant difference at $\mathrm{P}<0.05$.

Table 4b. Model 2: Multivariable Logistic Regression for Associated Factors of Being "Less Stressed"

\begin{tabular}{llllllll}
\hline Variables & $\mathrm{B}^{*}$ & S.E. & Wald & df & OR & $95 \% \mathrm{Cl}$ & P-value $^{+}$ \\
\hline Age & -0.134 & 0.027 & 5.990 & 1 & 0.874 & $0.81-0.95$ & 0.003 \\
\hline Gender & 1.363 & 0.570 & 4.847 & 1 & 3.907 & $1.21-13.74$ & 0.028 \\
\hline Number of children in family & 0.075 & 0.016 & 0.080 & 1 & 1.078 & $0.64-1.82$ & 0.778 \\
\hline Emotional exhaustion & 4.035 & 0.336 & 34.841 & 1 & 56.543 & $11.35-213.09$ & $<0.001$ \\
\hline Depersonalization & 0.771 & 0.145 & 0.257 & 1 & 2.162 & $0.61-10.22$ & 0.612 \\
\hline Personal accomplishment & -1.864 & 0.613 & 6.981 & 1 & 0.155 & $0.04-0.50$ & 0.003 \\
\hline
\end{tabular}

'Statistically significant difference at $\mathrm{P}<0.05$.

(Table $4 \mathrm{a}$ and Table $4 \mathrm{~b}$ ), several factors were independently associated with low levels of stress. Both models showed that younger age and male gender were predictors of "being less stressed”. Furthermore, high stress level was associated with high degree of emotional exhaustion (OR 56.543; 95\% CI 11.35-213.09; $\mathrm{P}<0.001)$ and lack of personal accomplishment (OR 0.155; 95\% CI 0.04$0.50 ; \mathrm{P}=0.003)$.

\section{Discussion}

The results of our study showed a high level of stress and burnout syndrome among the doctors interviewed. The most common causes of stress analysed in our study were administrative burden, constant changes of legislation, overwork with a large number of patients and health care insurance demands. The results of other studies also showed a high level of stress in interviewed doctors. A study conducted in Ireland (11) showed that $37 \%$ of interns met the criteria for psychological distress. A large percentage (55.4\%) of the subjects recruited into this study had high levels of emotional exhaustion, 51.5\% had a high level of depersonalization, and $41.6 \%$ had a low level of personal accomplishment. The subjects in this study had lower stress levels, but a higher risk for de- 
velopment of burnout syndrome than the subjects in our study.

A study conducted in the UK showed that $56.5 \%$ oto-rhino-laryngologists were at high risk of developing stress and psychological morbidity, and $28.9 \%$ had a high risk for burnout syndrome (12). A study conducted in Germany among 453 hospital residents in medical training, working in 6 different medical specialties, showed that up to $17 \%$ of the physicians reported high levels of occupational distress and $9 \%$ reported high levels of depressive symptoms (13). In these studies, the subjects reported a high level of stress in a great percentage, but their level of stress was lower than in the subjects in our study.

Although occupational stress is present among doctors worldwide, the results of our study presented significantly higher levels of occupational stress than in other countries. In our conditions, the poor social and economic status of physicians certainly contributes to the presence of a high level of stress. The inadequate income of physicians in relation to their invested effort may also be considered an additional cause of stress. Burnout syndrome is present among physicians all over the world. Physician burn out in the United States has reached epidemic proportions and is rising rapidly, although burnout in other occupations is stable (14).

Large scale research into the prevalence of burnout syndrome at work in family physicians in 12 European countries (Bulgaria, Croatia, France, Greece, Hungary, Italy, Poland, Portugal, Sweden, Spain, Great Britain and Turkey) revealed that $43 \%$ examinees had high levels of emotional exhaustion, $35 \%$ high levels of depersonalization, 32\% low levels of personal satisfaction (15). Our results from the Primary Health Centre Banja Luka have shown that $20.9 \%$ of doctors suffer from a high level of emotional exhaustion, $43.2 \%$ a high level of depersonalization, and $36.9 \%$ a low level of personal accomplishment, which is in accordance with other countries. Research conducted among 123 Canadian family physicians (16) showed that $42.5 \%$ physicians have high levels of stress, while research conducted in Italy showed that $35.8 \%$ of doctors interviewed had a high level of stress (17). Interestingly enough, our analysis revealed $77.7 \%$ of doctors met the criteria for high levels of stress.

Considering the influence of age as a risk factor for burnout syndrome and high levels of stress, the research does not give a single answer. Some authors say that younger age is a risk factor for the onset of burnout syndrome (2) and as doctors gain more experience and grow older, the level of stress decreases and therefore the risk of burnout syndrome itself decreases. Other authors consider that overworked persons and persons exposed to frequent interpersonal conflicts over a long period of time have emotional exhaustion symptoms to a large extent (18). Long-term constant contact with patients and exposure to other risk factors from the working environment may increase the level of stress and the risk of syndrome onset (19). The results of a study conducted among family physicians in the Republika Srpska showed that older age is an important risk factor for a high level of stress and the onset of emotional exhaustion i.e. burnout syndrome (20). Furthermore, we identified female gender, emotional exhaustion and a lack of personal accomplishment as important predictors of a high level of stress.

Burnout syndrome is a common psychological state that may affect human healthcare providers due to their prolonged exposure to job stressors (21). The rates of burnout symptoms can be associated with adverse effects on patients, the healthcare workforce, costs and physicians' health. This problem results in negative impacts on physicians, patients and the healthcare organization and system (22). Stress related anxiety 
and burnout may result in increased absenteeism and disability, decreased patient satisfaction and increased rates of medical error (23). These are the main reasons for considering preventive measures for burnout. Numerous authors have investigated strategies for prevention and treatment of persons affected by occupational stress and burnout. The research results are diverse, but most authors show that an individual approach has the best results. The interventions for prevention or alleviation of burnout that are mostly recommended are: shortening of working hours, additional continuous training, stress-management, self-care, communication skills training, etc. $(24,25)$.

\section{Limitations of the Study}

The study included a relatively small number of subjects and was conducted in only one Primary Health Care Centre. To obtain better information about the presence of burnout syndrome throughout the country, further research should include more health care institutions and more subjects.

\section{Conclusion}

The research results showed high levels of stress and a high risk for burnout syndrome in doctors in primary health care. It appears that older doctors who have a longer length of service have significantly higher levels of emotional exhaustion compared to younger doctors with a shorter length of service. Observing the results of our research, a high level of stress was associated with older age, female gender, longer length of service, as well as with a high degree of emotional exhaustion and a lack of personal accomplishment. In order to prevent the onset of this syndrome, it is necessary to establish a balance between professional and family obligations, and the ability to deal with stressful situations is of special importance in prevention of burnout syndrome.

What Is Already Known on this Topic

Burnout syndrome is present in different occupations, especially in persons that work with other people. Healthcare work is one of the professions that carries the greatest risk of burnout syndrome. Numerous studies worldwide have shown the high prevalence of burnout syndrome among different profiles of healthcare workers.

\section{What this Study Adds}

A small amount of research on this topic has been conducted in Bosnia and Herzegovina, and we hope that this research will contribute to a better insight into the problem of the prevalence of burnout syndrome in primary care physicians in our country.

Acknowledgements: We would like to thank all the physicians employed at the Primary Health Care Centre, Banja Luka, that took part in this research by filling in the questionnaires, and enabling us to conduct this study.

Authors' Contributions: Conception and design: KS, $\mathrm{VP}$ and BM; Acquisition, analysis and interpretation of data: KS, VP, BM and BS; Drafting the article: KS, VP, BM and BS; Revising it critically for important intellectual content: KS, VP, BM and BS; Approved final version of the manuscript: KS, VP, BM and BS.

Conflict of Interest: The authors declare that they have no conflict of interest.

\section{References}

1. Maslach C, Schaufeli WB, Leiter MP. Job burnout. Annu Rev Psychol. 2001;52:397-422.

2. Peterson U. Stress and burnout in healthcare workers. Stockoholm: Karolinska Institutet; 2008.

3. Maslach C. Job burnout: new directions in research and intervention. Curr Dir Psychol Sci. 2003;12:189-92.

4. Amoafo E, Hanbali N, Patel A, Singh P. What are the significant factors associated with burnout in doctors? Occup Med (Lond). 2015;65(2):117-21.

5. Singh P, Aulak DS, Mangat SS, Aulak MS. Systematic review: factors contributing to burnout in dentistry. Occup Med (Lond). 2016;66(1):27-31.

6. Vandenbroeck S, Van Gerven E, De Witte H, Vanhaecht K, Godderis L. Burnout in Belgian physicians and nurses. Occup Med (Lond). 2017;67(7):546-54. 
7. Dagrada H, Verbanck P, Kornreich C. General practitioner burnout: risk factors [in French]. Rev Med Brux. 2011;32(4):407-12.

8. Girdano DA, Everly GS, Dusek DE. Controlling Stress and Tension. Needham Heights, MA: Allyn \& Bacon; 1996.

9. Maslach C, Jackson S. The measurement of experienced burnout. J Organ Behav. 1981:2:99-113.

10. Shaufeli WB, Leiter MP, Maslach C, Jackson SE. Maslach Burnout Inventory - General Survey. The Maslach burnout inventory - test manual. 3rd ed. Palo Alto, CA: Consulting Psychologists Press; 1996.

11. Hannan E, Breslin N, Doherty E, McGreal M, Moneley D, Offiah G. Burnout and stress amongst interns in Irish hospitals: contributing factors and potential solutions. Ir J Med Sci. 2018;187(2):301-7.

12. Vijendren A, Yung M, Shiralkar U. Are ENT surgeons in the UK at risk of stress, psychological morbidities and burnout? A national questionnaire survey. Surgeon. 2018;16(1):12-9.

13. Bernburg M, Vitzthum K, Groneberg DA, Mache S. Physicians' occupational stress, depressive symptoms and work ability in relation to their working environment: a cross-sectional study of differences among medical residents with various specialties working in German hospitals. BMJ Open. 2016;6(6):e011369.

14. Rothenberger DA. Physician Burnout and WellBeing: A Systematic Review and Framework for Action. Dis Colon Rectum. 2017;60(6):567-76.

15. Soler JK, Yaman H, Esteva M, Dobbs F, Asenova RS, Katic M, et al. Burnout in European family doctors: the EGPRN study. Fam Pract. 2008;25(4):245-65.
16. Lee FJ, Stewart M, Brown JB. Stress, burnout, and strategies for reducing them: what's the situation among Canadian family physicians? Can Fam Physician. 2008;54(2):234-5.

17. Tremolada M, Schiavo S, Tison T, Sormano E, De Silvestro G, Marson P, et al. Stress, burnout, and job satisfaction in 470 health professionals in 98 apheresis units in Italy: A SIdEM collaborative study. J Clin Apher. 2015t;30(5):297-304.

18. Michaels RM. Physician burnout. Pa Med. 1996;99(5):18-21.

19. Gundersen L. Physician burnout. Ann Intern Med. 2001;135(2):145-8.

20. Stanetić K, Tesanović G. Influence of age and length of service on the level of stress and burnout syndrome. Med Pregl. 2013;66(3-4):153-62.

21. Romani M, Ashkar K. Burnout among physicians. Libyan J Med. 2014;9:23556.

22. Wisetborisut A, Angkurawaranon C, Jiraporncharoen W, Uaphanthasath R, Wiwatanadate P. Shift work and burnout among health care workers. Occup Med (Lond). 2014;64(4):279-86.

23. Regehr C, Glancy D, Pitts A, LeBlanc VR. Interventions to reduce the consequences of stress in physicians: a review and meta-analysis. J Nerv Ment Dis. 2014;202(5):353-9.

24. Feteh VF, Njim T, Nji MAM, Ayeah CM, Sama $\mathrm{CB}$, Tianyi FL. Prevalence and determinants of burnout syndrome among physicians in Cameroon: a research proposal. BMC Res Notes. 2017;10(1):508.

25. West CP, Dyrbye LN, Shanafelt TD. Physician burnout: contributors, consequences and solutions. J Intern Med. 2018;283(6):516-29. 